MATEC Web of Conferences 11,01003 (2014)

DOI: $10.1051 /$ matecconf / 20141101003

(C) Owned by the authors, published by EDP Sciences, 2014

\title{
Investigation into the Effect of the Duration of Exposure on the Behaviour of GPC at Elevated Temperatures
}

\author{
Muhammad Talha Junaid ${ }^{1}$, Amar Khennane ${ }^{1}$ and Obada Kayali ${ }^{1}$ \\ ${ }^{1}$ University of New South Wales at the Australian Defence Force Academy, School of Engineering and Information \\ Technology, Canberra, Australia
}

\begin{abstract}
Ordinary Portland Cement (OPC) Concrete has long been used in the construction industry as a primary material owing to its versatility, superior performance, low cost, easy workability and availability of accepted standards of practice. The readily available raw materials for the manufacture of cement, and subsequently for concrete itself, have been a driving force for the acceptance of concrete as a construction material worldwide. Recently however, OPC concrete has come under scrutiny over its large carbon footprint. This is largely due to the energy intensive manufacturing process of cement and the extensive use of virgin material in cement production. Focus is therefore shifting to engineer new construction materials that offer similar advantages to that of OPC concrete while being environmentally friendly. Geopolymer Concrete (GPC) is such a material. It has emerged during the last decades, and has been found to possess excellent engineering properties as well as enormous benefits on the sustainability front. The current study is conducted to investigate the compressive strength of GPC up to temperatures of $1000^{\circ} \mathrm{C}$ for varying duration of exposure time. It was found that when tested at temperatures of $600^{\circ} \mathrm{C}, 800^{\circ} \mathrm{C}$ and $1000^{\circ} \mathrm{C}$, the GPC samples exhibited a higher compressive strength (8-18\%). However, the samples tested after cooling recorded a residual compressive strength $25-50 \%$ lower than the ambient strength. Yet, the residual strength of GPC is significantly higher than that of OPC. The duration of exposure time was found to have an insignificant effect on the strength properties of GPC, especially at higher temperatures. Scanning Electron Microscopy (SEM) was used to reveal the changes to the micro-structure that took place after exposure to high temperatures and to get a useful insight into the behaviour of geopolymers.
\end{abstract}

\section{Introduction}

Alkali liquids (usually a soluble metal hydro-oxide and/or alkali silicate) can be used to react with silica $\left(\mathrm{SiO}_{2}\right)$ and alumina $\left(\mathrm{Al}_{2} \mathrm{O}_{3}\right)$ rich natural materials, like metakaolin or with industrial by-products, like Fly Ash (FA), Silica Fume (SF), Rice Husk Ash (RHA) or Slag to produce binders [1-3]. Though the details are still debated, many researchers agree that the basic reaction mechanism takes place in three stages; namely: dissolution of $\mathrm{Si}$ and $\mathrm{Al}$ from the source material, hydrolysis or gelation, and condensation forming a 3D network of silico-aluminates also termed as the 'geopolymer backbone' [1, 2, 4-8]. Davidovits [2] describes geopolymerization as an exothermic reaction, and has schematised it as follows:

\section{Si-Al source + Silicates + Water + Alkaline Liquid $\rightarrow$ Geopolymer Precursor} Geopolymer Precursor + Alkaline lons $\rightarrow$
Geopolymer Backbone

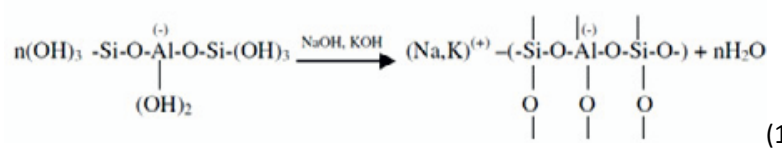

GPC does not require any hydraulic binder. The role of fly ash (FA) in GPC is entirely different from that it plays when used as a cement replacement material in OPC concrete to enhance certain properties such as workability or to reduce the heat of hydration. In such cases FA has no pronounced effect on the strength of concrete [9] especially early strength. In GPC, however, FA is the sole source of aluminosilicates for reaction with the alkaline solution to form the binder, and is thus a critical factor in strength development.

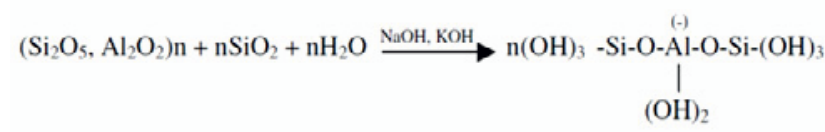

This is an Open Access article distributed under the terms of the Creative Commons Attribution License 2.0, which permits unrestricted use, distribution, and reproduction in any medium, provided the original work is properly cited. 


\subsection{Changes at High Temperatures to OPC and GPC}

Owing to its very different chemistry as compared to OPC, GPC behaves very differently when exposed to high temperatures. It is widely accepted [10] that OPC loses over $80 \%$ of strength when the temperature exceeds $800^{\circ} \mathrm{C}$. This is due to inherent physical stresses caused by the introduction of heat energy, and the chemical breakdown of the hydrated phases in the cement paste [11]. There have been a number of general findings published in the literature that cover the effects of high temperature on OPC concrete, though the extent may depend on several factors like water-cement ratio, curing condition, aggregate type and size, type of admixture, and so on. These are summarised as:

1. The loss of free water and chemically bound water in the $\mathrm{CaOH}_{2}$ through dehydroxylation leads to significant dehydration of the concrete, loss of chemical bonding, and spalling [11].

2. The disparity in the amount of thermal expansion in the aggregate in comparison to the shrinkage of the OPC cement means that micro stresses are induced and result in micro-cracking.

3. The type of aggregate has a significant effect on the strength-temperature relationship of concrete. Calcareous aggregates decarbonise at temperatures above $800^{\circ} \mathrm{C}$. This can be avoided by using siliceous aggregates [10]. Yet quartz also undergoes a phase change at around $400^{\circ}$ $\mathrm{C}$ (configuration $\alpha$ to $\beta$ ), which results in very high thermal expansion.

4. The rate of heating has little effect on the sample so long as the temperature gradient is below 10 degrees per centimetre towards the core [10].

In previous research focusing on the residual properties of geopolymer paste and mortar, it has been found that fly ash based geopolymers have retained most of their residual strength after being exposed to an elevated temperatures [11-17]. This may be attributed to the fact that not only does GPC not use a hydraulic binder it has a large number of nano-pores formed by escaping water during the geopolymerization process [18]. Such pores act as a conduit for water as it escapes the structure and thus reduces the formation of cracks due to the pressure created by internally overheated vapour. This means that there is minimal spalling and damage to the geopolymer structure at elevated temperatures. The high strength retention can also be due to the gradual sintering of the un-reacted fly ash that is present within the concrete [14-16]. Sintering occurs when very fine powders (such as fly ash) are heated to high temperatures causing molecules to diffuse to the boundaries of the particles, which causes the particles to partially fuse together. This means that the unused fly ash powder, which is responsible for local weaknesses before exposure, bonds covalently into a strong solid material within the concrete.

\section{Materials and Testing}

The GPC samples were made using Grade D Sodium Silicate and 12M Sodium Hydroxide prepared from 98\% pure flakes as alkaline solutions; while ASTM Class F Fly Ash was used as the main aluminium and silicate source. Cylinders with nominal measurements of $75 \mathrm{~mm}$ diameter and $150 \mathrm{~mm}$ height were mixed and cast using the procedure described in [19]. The samples, after an initial rest period, were cured for 72 hours at $80^{\circ} \mathrm{C}$. They were then placed in an environmental room with a relative humidity of $50 \%$ and a temperature of $23^{\circ} \mathrm{C}$ till the time of testing. All testing was done at 7 days after mixing. The composition of mix M-1 and the ambient mean compressive strength $\left(f_{c}^{\prime}\right)$ is given in Table 1 .

Table 1: Composition and Mean Compressive Strength $\left(f_{c}\right)$ of the GPC Samples

\begin{tabular}{|c|c|c|}
\hline & & M-1 \\
\hline Fly Ash & $(\mathrm{kg} / \mathrm{m3})$ & 420 \\
\hline $\mathrm{NaOH}$ & $(\mathrm{kg} / \mathrm{m} 3)$ & 44 \\
\hline $\mathrm{Na}_{2} \mathrm{SiO}_{3}$ & $(\mathrm{~kg} / \mathrm{m} 3)$ & 110 \\
\hline Coarse & $(\mathrm{kg} / \mathrm{m3})$ & 1120 \\
\hline Fine & $(\mathrm{kg} / \mathrm{m} 3)$ & 650 \\
\hline $\begin{array}{c}\text { Free } \\
\text { Water }\end{array}$ & $(\mathrm{kg} / \mathrm{m3})$ & 28.5 \\
\hline $\mathrm{SP} \mathrm{P}^{*} \mathrm{VM} \mathrm{M}^{\wedge}$ & $(\mathrm{kg} / \mathrm{m} 3)$ & 7.2 \\
\hline$f_{c}^{\prime}$ & $(\mathrm{MPa})$ & 44 \\
\hline
\end{tabular}

The samples were grinded, measured and weighed in accordance with Australian Standards [20] to establish the ambient compressive strength. The grinded samples were then put in a furnace and heated to desired temperatures of $100^{\circ} \mathrm{C}, 350^{\circ} \mathrm{C}, 600^{\circ} \mathrm{C}, 800^{\circ} \mathrm{C}$ and $1000^{\circ} \mathrm{C}$. The heating rate was set at $4.5^{\circ} \mathrm{C} / \mathrm{min}$ for all cases, which is consistent with RILEM 129-MHT standard recommendations [21]. The time required for the samples to reach equilibrium was established by embedding $\mathrm{K}$ Type thermo couples into the sample core as well as on the surface and in the air. This data was collected and plotted against time. It was found that irrespective of the target temperature, the time required to reach thermal equilibrium was around $90 \mathrm{~min}$ as seen in Figure1. The target temperature was maintained for 2 and 6 hours respectively after equilibrium was established to study the effect of duration of exposure on strength of GPC. At this time the samples were removed from the furnace. Hot strength was determined by testing the sample immediately after removing it from the furnace. As the testing duration was rather short (under 2 mins), it was established that the heat loss during testing was insignificant to affect the results in any way. Samples to be tested for residual strength were removed from the furnace and kept in an identical switched off furnace to cool down to ambient temperature overnight. These samples were then weighed, measured and tested as per standards to obtain their residual strengths. After strength 
testing, the samples were collected and marked in air tight containers to undergo Scanning Electron Microscopy (SEM) for changes to their microstructure. A Hitachi TM3000 instrument was used for this purpose.

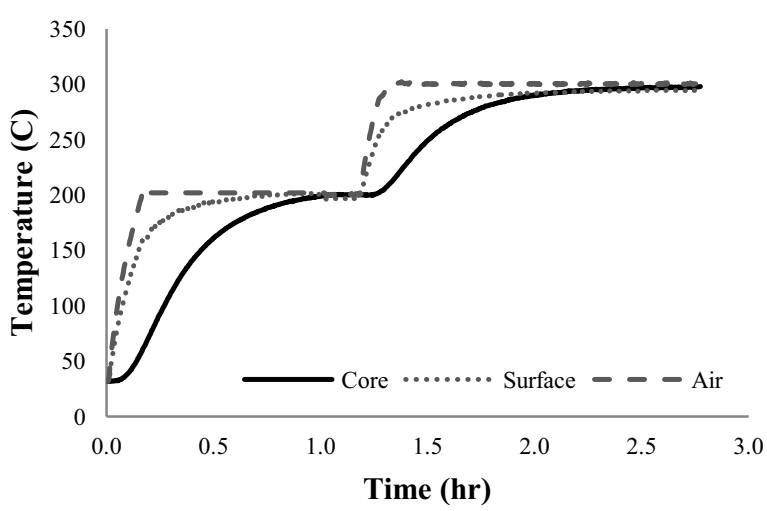

Figure 1: Two Step Temperature Rise to Establish Time for Core Equilibrium

\section{Results and Discussion}

\subsection{Hot and Residual Strength}

The measured strength was normalized against the ambient strength. The normalized hot strength is plotted in Figure 2. It can be noticed that for the lower temperatures of $100^{\circ} \mathrm{C}$ and $350^{\circ} \mathrm{C}$, GPC looses $15-25 \%$ of its strength in the first 2 hours of heating. After this initial loss the retained strength flattens out to about $80 \%$ of ambient at the 6 hour mark. The early loss in strength, especially at $100^{\circ} \mathrm{C}$, can be attributed to the loss of free water in the GPC system. The escaping water leaves behind pores and voids compromising the integrity of the matrix. Moreover, the temperature is not high enough, or maintained long enough, for chemical changes to occur within the matrix, which results in strength gains, as is the case for the high temperature tests. However, a slight increase is strength (around 5-8\%) is noticed as the heating reaches the 6 hour mark. This indicates that the sustained heat has facilitated the reaction between the unreacted FA particles and the alkaline solution resulting is a moderate strength gain.

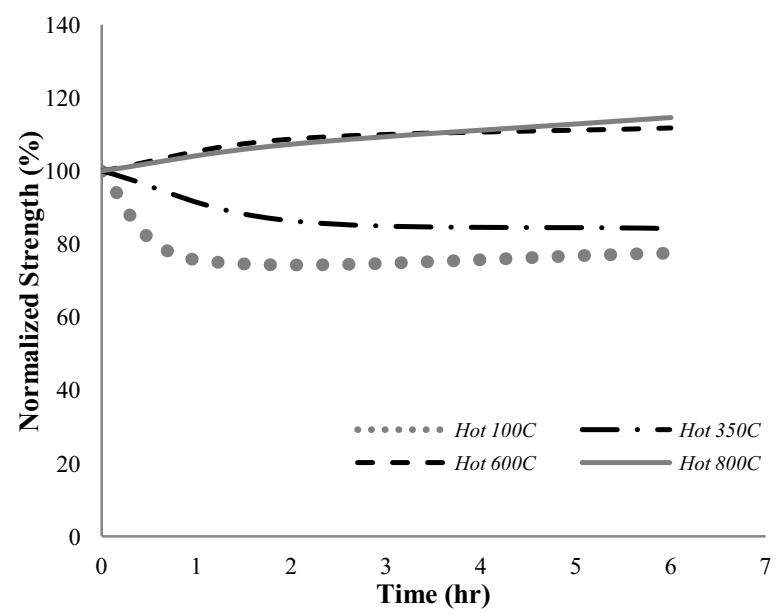

Figure 2: Normalized Hot Strength of GPC Samples
At $350^{\circ} \mathrm{C}$ the rate of strength loss is much slower as compared to $100^{\circ} \mathrm{C}$ heating. This can be attributed to the fact that the temperature is high enough for considerable amount of unreacted FA particles to undergo geopolymerization. The strength gained during this additional geopolymerization offsets the strength lost due to escaping water.

At much higher temperatures $\left(600^{\circ} \mathrm{C}\right.$ and $\left.800^{\circ} \mathrm{C}\right)$ GPC gains $10-15 \%$ strength throughout the heating period. This gain may be a result of complete geopolymerization in the matrix as well as additional molecular changes in the system and are discussed further in the subsequent section. This gain however, flattens out after the first thermal equilibrium is reached and no further strength gain is observed with continued heating.

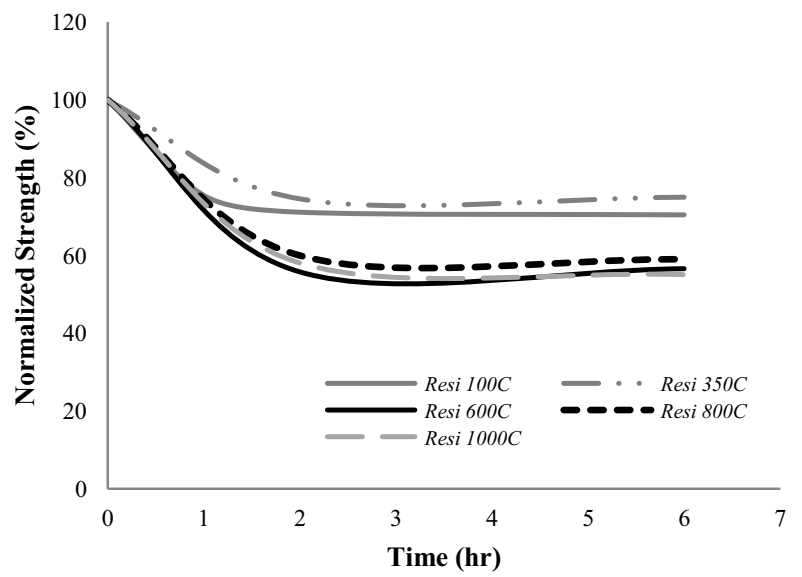

Figure 3: Normalized Residual Strength of GPC Samples

The normalized residual strength of GPC samples are shown in Figure 3. All GPC samples experienced a loss in strength when tested after cooling. Depending on the exposure temperature the percentage of strength lost varies between $25-50 \%$. At higher temperatures of $600^{\circ} \mathrm{C}$, $800^{\circ} \mathrm{C}$ and $1000^{\circ} \mathrm{C}$ the strength loss is between $40-50 \%$ down from a $15 \%$ increase when tested hot. Even at relatively lower temperatures of $100^{\circ} \mathrm{C}$ and $350^{\circ} \mathrm{C}$ the residual strength is around $10 \%$ lower than the hot strength (Figure 4). One possible explanation of this reduction in strength may be the incompatibilities between the different phases of concrete (matrix and
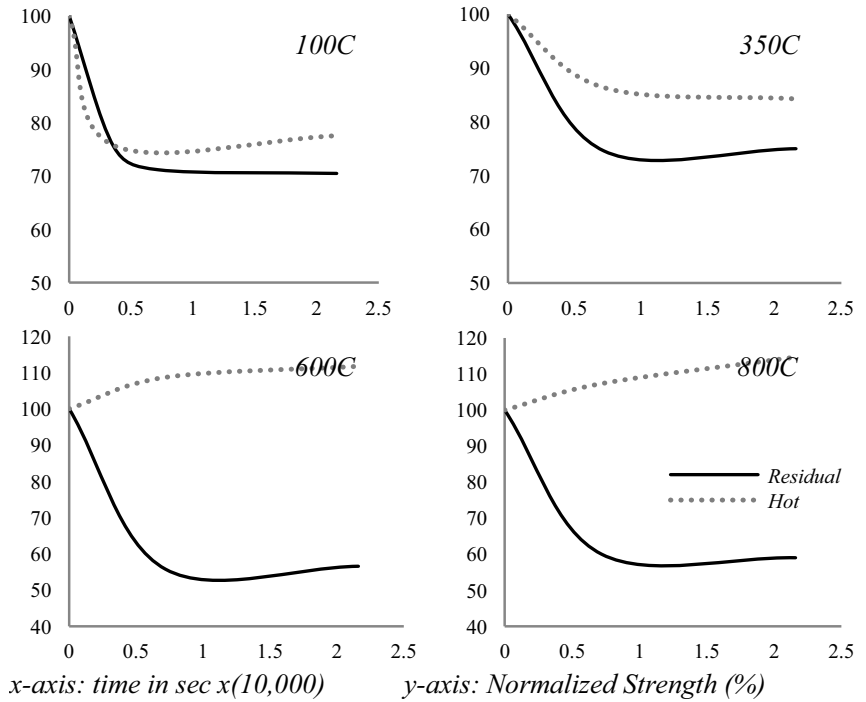

Figure 4: Hot and Residual Strength for Each Individual Temperature 
aggregates). During cooling the stresses caused by the thermal incompatibilities of these materials induce cracking resulting in lower strengths.

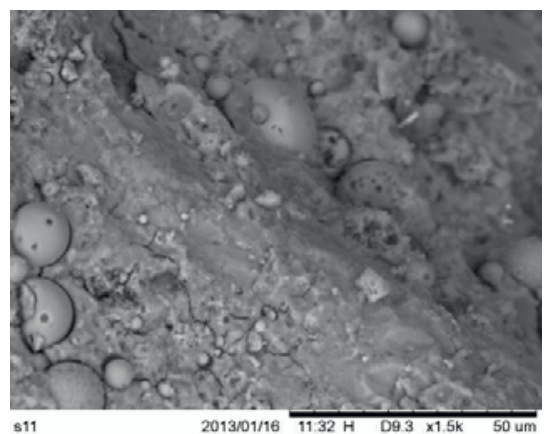

a) Before Exposure, cured at $80^{\circ} \mathrm{C}$

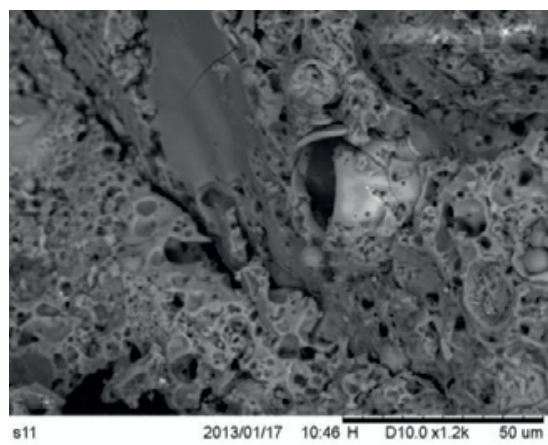

d) After Exposure to $600^{\circ} \mathrm{C}$ for 2 hours

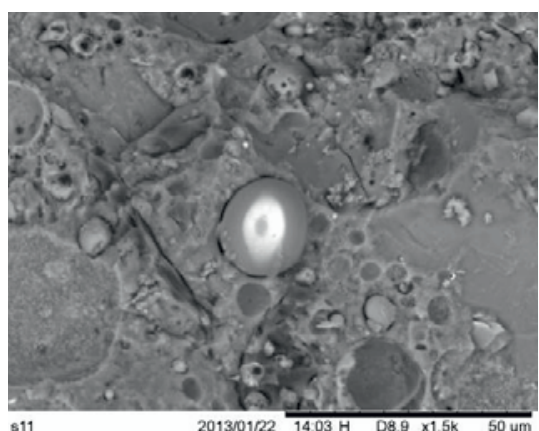

b) After Exposure to $100^{\circ} \mathrm{C}$ for 2 hours

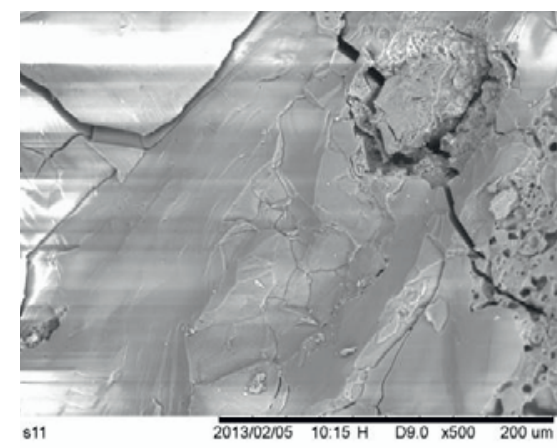

e) After Exposure to $800^{\circ} \mathrm{C}$ for 6 hours

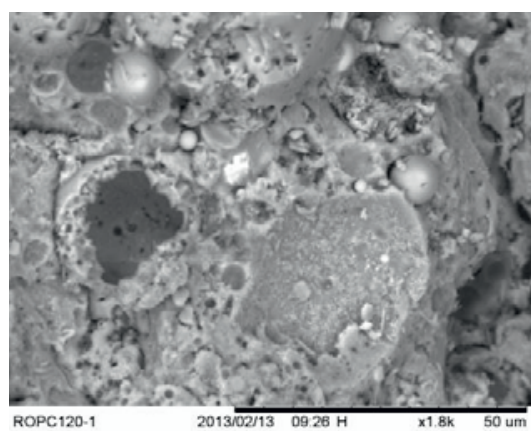

c) After Exposure to $350^{\circ} \mathrm{C}$ for 2 hours

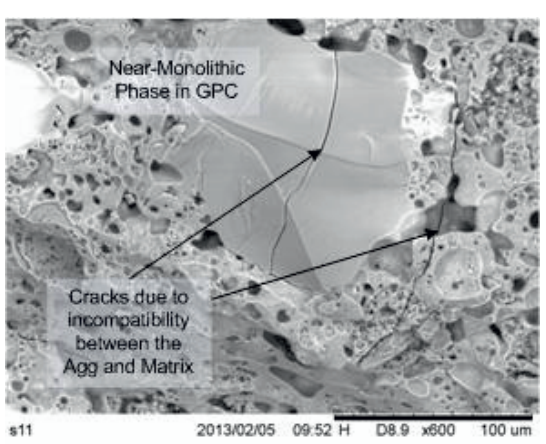

f) After Exposure to $1000^{\circ} \mathrm{C}$ for 2 hours

Figure 5: SEM Micrographs of GPC Samples After Exposure to Different Temperatures

\subsection{Scanning Electron Microscopy (SEM)}

Scanning Electron Microscopy (SEM) was used to obtain the micrographs of the GPC samples before and after exposure to high temperatures. The micrographs clearly show a significant change in the structure of the GPC matrix and gives valuable insight into the strength behaviour of these samples. Figures 5 ( $a$ and $b$ ) show that there is no considerable change in the structure of the GPC, with several unreacted FA spheres still scattered throughout the sample. Moreover, in Figure $5 \mathrm{~b}$, several micro-cracks can be seen in the sample which may be a result of thermal incompatibilities between the matrix and aggregates. They may also have been caused by the stress experienced during testing. Also noticeable in the micrographs are voids, which may have been caused by escaping water or lack of compaction. After the samples have been exposed to $350^{\circ} \mathrm{C}$ (Figure $5 \mathrm{c}$ ), it is apparent that the FA particles have collapsed with extensive pitting visible throughout the micrograph. This supports the hypothesis that the increase in temperature facilitated the geopolymerization within the matrix. However, at this temperature several unreacted FA spheres are still visible.

The pitting, diffusion and collapsing of FA spheres is widespread when the GPC samples are exposed to $600^{\circ} \mathrm{C}$. There are no unreacted FA spheres visible at this temperature while the matrix resembles a solidified mass of near molten matter. Also visible is the near-monolithic phase in GPC, although at this temperature these are far and few in between. This clearly shows a change in the material behaviour of GPC at this temperature and points to a viscous-flow-type phenomenon generally attributed to glass and metals and is reported by Pan [17]. As the temperature is increased further to $800^{\circ} \mathrm{C}$ and then to $1000^{\circ} \mathrm{C}$, the near-monolithic phase in GPC is found more frequently through the matrix. This signifies the sintering of the fly ash particles and explains why at these high temperatures GPC exhibits higher compressive strength. However, upon cooling, due to thermal shock or incompatibilities within the concrete, extensive cracking is evident in the samples. This accounts for the considerable loss of strength observed between hot and residual strength of GPC at higher temperatures. It was also observed that the duration of exposure has no effect on the microstructure of the GPC samples.

\section{Conclusions}

1. Most changes in strength and microstructure of GPC samples occur in the first 2 hours of exposure to high temperatures. 
2. After the initial changes have taken place the duration of exposure has an insignificant effect on the strength of GPC samples.

3. Microstructural changes in GPC occur rather quickly over a short period of time after equilibrium temperature is reached.

4. At relatively low exposure temperatures the movement of water within or from the GPC system has a considerable negative effect on its strength. However, as the temperature is increased further, the microstructural changes offset this strength loss caused by movement of water and GPC experiences a gain in strength.

5. For all tests conducted the residual strength of GPC is always less than the hot strength irrespective of exposure temperature. However, this difference is magnified at high temperature ranges.

\section{References}

[1] J. Davidovits, "Soft Mineralogy and Geopolymers," in Proceedings of the Geopoolymer 88 International Conference, France, 1988.

[2] J. Davidovits, "Geopolymers Inorganic polymerie new materials," Journal ofThamalAnalysis, vol. 37, pp. 1633-1656, 1991.

[3] N. A. Lloyd and B. V. Rangan, "Geopolymer Concrete with Fly Ash," presented at the Second International Conference on Sustainable Construction Materials and Technologies, Italy, 2010.

[4] I. Diaz-Loya, et al., "Mechanical Properties of FlyAsh-Based Geopolymer Concrete," ACI Materials Journal, vol. 108, pp. 300-308, 2011.

[5] A. Fernandez-Jimenez and A. Palomo, "Alkaline Activation of Fly Ashes. Manufacture of Concrete Not Containing Portland Cement," presented at the International RILEM Conference on the Use of Recycled Materials in Buildings and Structures, 2004.

[6] T. J. Gourley and G. B. Johnson, "Development in Geopolymer Precast Concrete," in International Workshop on Geopolymers and Geoplymer Concrete, Perth, Australia, 2005.

[7] W. D. A. Rickard, et al., "Assessing the suitability of three Australian fly ashes as an aluminosilicate source for geopolymers in high temperature applications," Materials Science and Engineering A, vol. 528, pp. 3390-3397, 2011.

[8] I. Diaz-Loya, et al., "Factors Affecting the Suitability of Fly Ash as Source Material for Geopolymers," Fuel, vol. 89, pp. 992-996, 2010.

[9] A. Neville, Properties of Concrete, 4th ed.: Longman Group Limited, 1995.

[10] U. Schneider, "Concrete at high temperatures-a general review," Fire Safely Journal, vol. 13, pp. 5568, 1988.

[11] M. Guerrieri, et al., "Residual strength properties of sodium silicate alkali activated slag paste exposed to elevated temperatures," Materials and Structures, vol. 43, pp. 765-773, 2010.

[12] A. Elimbi, et al., "Effects of calcination temperature of kaolinite clays on the properties of geopolymer cements," Construction and Building Materials, vol. 25, pp. 2805-2812, 2011.
[13] J. v. Jaarsveld, et al., "The effect of composition and temperature on the properties of fly ash- and kaolinite-based geopolymers," Chemical Engineering Journal, vol. 89, pp. 63-73, 2002.

[14] D. Kong and J. G. Sanjayan, "Damage behavior of geopolymer composites exposed to elevated temperatures," Cement \& Concrete Composites, vol. 30, pp. 986-991, 2008

[15] D. Kong and J. G. Sanjayan, "Effect of elevated temperatures on geopolymer paste, mortar and concrete," Cement and Concrete Research, vol. 40, pp. 334-339, 2009.

[16] D. Kong, et al., "Comparative performance of geopolymers made with metakaolin and fly ash after exposure to elevated temperatures," Cement and Concrete Research, vol. 37, pp. 1583-1589, 2007.

[17] Z. Pan and J. G. Sanjayan, "Stress-strain behaviour and abrupt loss of stiffness of geopolymer at elevated temperatures," Cement \& Concrete Composites, vol. 32, pp. 657-664, 2010

[18] D. Hardjito and B. V. Rangan, "Development and Properties of Low-Calcium Fly Ash-Based Geopolymer Concrete," Curtin University of Technology2005.

[19] M. T. Junaid, et al., "Mix Design Procedure for Alkali Activated Fly Ash-based Geopolymer Concretes," in International Conference on Engineering and Applied Science, Beijing, China, 2012, pp. 139-152.

[20] S. Australian, "AS 1010.9-1999: Determination of the Compressive Strength of Concrete Specimens," in Methods of Testing Concrete, ed, 1999.

[21] RILEM, "Test methods for mechanical properties of concrete at high temperatures. Recommendations Part 6: Thermal Strains," vol. 129-MHT, ed, 1997. 